secretary-general, was the first meeting of representatives of the countries of the Far East to discuss common problems of forestry and timber utilization. The new post resulted from this conference, which recommended that a forestry and forest products working group be set up in the region, to be composed of staff members of the Forestry and Forest Products Division. The functions of the working group will be, among others, to arrange for exchange of technical and professional information between countries ; to arrange for a meeting of technical experts to discuss the standardization of grades and sizes of timber and plywood, nomenclature and trade terms; and to arrange for an exchange of specialists, technicians and students between countries. Dr. Huberman recently travelled through most of the countries of south-east Asia, discussing forestry problems with those officials who are concerned with forest management, trade, soil conservation practices, etc. A graduate of Michigan State College, Dr. Huberman holds a master's degree in forestry and a Ph.D. from Yale University; and before joining the Food and Agriculture Organisation in 1946 he spent fifteen years with the United States Forest Service working in sylvicultural research, private forest management, and national forest administration.

\section{Science Clubs}

A programme for the stimulation and development of science clubs throughout the world was agreed to at a meeting of science club leaders held in Paris at Unesco/House during July 15-16. Representatives from nigle countries, meeting under the chairmanship of Dr.Watson Davis, director of Science Service in the United States, agreed to propose that Unesco tgke steps to recommend to the Governments of Member States that science clubs, which represent a form of activity of general interest, be given effective support. It was suggested that primary and secondary school curricula might be re-examined with the view of reducing, if necessary, the number of compulsory school hours to permit more free time for science clubs. Unesco was also asked to consider the possibility of establishing a permanent central office of information for science clubs. It was also recommended that science clubs concern themselves with the study of scientific method and the social implications of science, and that there be an active link-up with the annual Unesco discussion theme.

\section{Physics Researc in Western Germany}

THE plysigfsocieties of the Western German Zone have iss ed mgrandum urging political authoritieg and the not to grudge financial help to plades of research. In spite of the well-known fact that the physics of to-day is the technology of for-morrov, heavy restrictions have been introduced since the end of the War, and particularly since the currency reform, in the budgets of all university labolatories. Staff has been dismissed and vacant chpirs have not been filled. Although Germany has become poor and should be thrifty, it can only live on its output and will soon be considerably poorer still, unless more means than ever before (proportionally) are spent on the re-equipment of its institutes and the training of young scientific workers. The memorandum points out that the number of students in the Western Zone universities has doubled; but science, cut off from the world for many years, has fallen behind and is unable to catch up with other countries for lack of apparatus and materials, so that men of science prefer to work abroad. Modern physics, even if carried on in the least ambitious style, requires very expensive equipment, and the great complication of the work demands more technical as well as clerical staff. "No industrial laboratory works as uneconomically as do the university laboratories, where owing to lack of staff the professors and scientific assistants must do almost all the work themselves." Further, if, as is now the case, one scientific assistant must suffice for a hundred students, both the work of the assistant and the training of the students suffer. The Notgemeinschaft der deutschen Wissenschaft can only supply a small portion of the needed funds, and the universities should have funds of their own, if work is to be undertaken independently of the approval of non-scientific bodies. At present, every trifle must be approved by a Government department and decisions are in consequence greatly delayed.

\section{Photoelectric Spectrometry Group H6}

Aт a meeting hell in Cambridge on July 16, 1948, the Photoelectric 5 ptrometry Group was formed with Dr. J. R. Edisoly, of the Research Department of Messrs. L fvensBros., Port Sunlight, as chairman. Although or givally conceived as a discussion group for usely of the Beckman spectrophotometer, the sche was later widened to cover other instruments of st nilar type. Among the activities envisaged were the holding of scientific meetings, the organising of collaborative tests, the maintenance of an accessories pool for the Beckman instrument, liaison with manufacturers of spectrophotometric equipment in Great Britain, and the publication of a bulletin. The first number of the Photoelectric Spectrometry Group Bulletin (obtainable from W. H. Storey, Hon. Sec. P.S.G., Unicam Instruments, Arbury Works, Cambridge; pp. 16 ; price 5s.) was issued in April and contains papers by Dr. E. R. Holiday on "Adaptation of the Hilger Spekker Photometer and Medium Spectrograph for Photoelectric Work", Dr. G. H. Beaven on "Notes on the Design, Operation and Maintenance of the Beckman Spectrophotometer", and Dr. J. R. Edisbury on "Relative Readings on Twenty-eight Beckman Spectrophotometers". Several notes on technique and accessories are also included. The Group has now completed its first year of operation and has held four well-attended scientific meetings, membership of the Group now standing at more than one hundred and thirty. The possibility of affiliation to one of the larger existing societies will be given consideration in due course.

Testing Electrical Circuit Breakers

THE Electricad 8 fearch Association has recently reported anfinacestifg development which has taken place in corn xion with its programme of research on gasplast fitcuit breakers. Normally the testing of circul bredors is carried out using as a power seurcp an alternator having a power rating comparable $\mathrm{mith}$ hat of one of the generators which would feed a power network. An important factor in the benviour of a circuit breaker in interrupting an alternating current is the rate of rise of voltage across the switch contacts after the extinction of the arc at the instant of zero current; for, if the voltage rises sufficiently rapidly, the gap between the separating contacts may be broken down and the arc re-established for a further half-period. The alternator employed by the Electrical Research Association for circuit-breaker tests is a $6 \cdot 6-\mathrm{kV}$., $10,000-\mathrm{kW}$. machine. It has been found that a 